\title{
Radiation exposure in the endovascular therapy of cranial and spinal dural arteriovenous fistula in the last decade: a retrospective, single-center observational study
}

\author{
Marcel Opitz ${ }^{1}$ Sebastian Zensen ${ }^{1} \cdot$ Denise Bos ${ }^{1} \cdot$ Yan $\mathrm{Li}^{1} \cdot$ Hanna Styczen $^{1} \cdot$ Axel Wetter $^{1,2} \cdot$ Nika Guberina $^{3}$. \\ Ramazan Jabbarli $^{4}$. Ulrich Sure ${ }^{4} \cdot$ Michael Forsting $^{1} \cdot$ Isabel Wanke $^{1,5} \cdot$ Cornelius Deuschl $^{1}$
}

Received: 4 July 2021 / Accepted: 8 September 2021 / Published online: 27 September 2021

(C) The Author(s) 2021

\begin{abstract}
Purpose This study aims to determine local diagnostic reference levels (DRLs) in the endovascular therapy (EVT) of patients with cranial and spinal dural arteriovenous fistula (dAVF).

Methods In a retrospective study design, DRLs and achievable dose (AD) were assessed for all patients with cranial and spinal dAVF undergoing EVT (I) or diagnostic angiography (II). All procedures were performed at the flat-panel angiographysystem Allura Xper (Philips Healthcare). Interventional procedures were differentiated according to the region of fistula and the type of procedure.

Results In total, 264 neurointerventional procedures of 131 patients with dAVF ( 94 cranial, 37 spinal) were executed between 02/2010 and 12/2020. The following DRLs, AD, and mean values could be determined: for cranial dAVF (I) DRL 507.33 Gy $\mathrm{cm}^{2}$, AD 369.79 Gy cm${ }^{2}$, mean 396.51 Gy cm${ }^{2}$; (II) DRL $256.65 \mathrm{~Gy} \mathrm{~cm}^{2}$, AD $214.19 \mathrm{~Gy} \mathrm{~cm}^{2}$, mean $211.80 \mathrm{~Gy} \mathrm{~cm}^{2}$; for spinal dAVF (I) DRL $482.72 \mathrm{~Gy} \mathrm{~cm}^{2}$, AD $275.98 \mathrm{~Gy} \mathrm{~cm}^{2}$, mean $347.12 \mathrm{~Gy} \mathrm{~cm}^{2}$; (II) DRL $396.39 \mathrm{~Gy} \mathrm{~cm}{ }^{2}$, AD $210.57 \mathrm{~Gy}$ $\mathrm{cm}^{2}$, mean $299.55 \mathrm{~Gy} \mathrm{~cm}^{2}$. Dose levels of EVT were significantly higher compared to diagnostic angiographies $(p<0.001)$. No statistical difference in dose levels regarding the localization of dAVF was found.

Conclusion Our results could be used for establishing DRLs in the EVT of cranial and spinal dAVF. Because radiation exposure to comparably complex interventions such as AVM embolization is similar, it may be useful to determine general DRLs for both entities together.
\end{abstract}

Keywords Radiation exposure $\cdot$ Arteriovenous fistula $\cdot$ Embolization $\cdot$ Interventional neuroradiology

Marcel Opitz

marcel.opitz@uk-essen.de

$1 \quad$ Institute of Diagnostic and Interventional Radiology and Neuroradiology, Faculty of Medicine University Hospital Essen, University Hospital Essen, Hufelandstrasse 55, 45147 Essen, Germany

2 Department of Diagnostic and Interventional Radiology, Neuroradiology, Asklepios Klinikum Harburg, Hamburg, Germany

3 Department of Radiotion Therapy, University Hospital Essen, West German Cancer Center, Essen, Germany

4 Department of Neurosurgery, University Hospital Essen, Essen, Germany

5 Department of Neuroradiology, Clinic Hirslanden, Zurich, Switzerland

\section{Abbreviations}

AD Achievable dose

AVM Arteriovenous malformation

CCF Carotid-cavernous fistula

DAP Dose area product

dAVF Dural arteriovenous fistula

DRLs Diagnostic reference levels

EVT Endovascular therapy

FOV Field of view

FT Fluoroscopy time

ICRP International Commission on Radiological Protection 


\section{Introduction}

Cranial dural arteriovenous fistulas (dAVFs) represent 10-15\% of all intracranial vascular malformations with arteriovenous shunting and belong to the most frequently acquired vascular lesions of the central nervous system $[1,2]$. The indication for treatment depends on the morphology of the cranial dAVF, the resulting probability of bleeding, and clinical presentation. High-grade fistulas type $2 \mathrm{~b}-5$ with cortical reflux classified by Cognard/Merland have a significantly higher risk of intracranial hemorrhage [3, 4]. In low-grade fistulas, type 1-2a by Cognard/Merland, a therapy refractory pulse-synchronous tinnitus is a typical treatment indication $[5,6]$. Over the past decade, endovascular therapy (EVT) of patients with cranial $\mathrm{dAVF}$ evolved as the first-line treatment with high occlusion rates, low risk profile, and very low recurrence rates [7-9]. However, microsurgery, stereotactic radiosurgery, or combined therapy approaches remain as alternative treatment options.

Spinal dAVF represents the most common subset of spinal vascular malformations, accounting for approximately $70 \%$. Nevertheless, it is a rare, probably underdiagnosed pathology with an incidence of only 5-10 new cases per million inhabitants per year [10]. In contrast to cranial dAVF, hemorrhage in spinal dAVF is very rare [11]. Nevertheless, a causal therapy is required in all patients because only the occlusion of the fistulous point will prevent progressive myelopathy caused by venous hypertension [12, 13]. Microneurosurgical occlusion of the fistula was the method of choice for many years, but more recently, endovascular techniques have augmented the therapeutic spectrum. Up to date, both endovascular and surgical treatment have been proven to be safe and effective [14, 15].

The role of DRLs in interventional neuroradiology has significantly increased over the last years as the guidelines for radiation protection have been updated recently [16, 17]. These minimally invasive fluoroscopically guided procedures are a highly effective treatment option for various neurovascular conditions. However, because of the complexity of the pathologies, some procedures may comprise high radiation exposure to patients and staff members [18, 19], leading to an increased potential deterministic and stochastic risk of developing radiation-induced cancer [20]. In order to raise dose awareness and in the long term optimize the modification of equipment, technique, and imaging parameters, several professional and regulatory organizations, such as the International Commission on Radiological Protection (ICRP), are proclaiming the necessity for diagnostic reference levels (DRLs), especially in interventional neuroradiology [21-23].

Data on radiation exposure of EVT in patients with cranial and spinal dAVF remain scarce. Hence, the goal of this study was to establish local DRLs at our department utilizing contemporary digital equipment.

\section{Methods}

\section{Patient cohort}

This retrospective study was approved by the ethical committee of our institution (20-9758-BO) and is conducted in accordance with the principles of the Declaration of Helsinki. All procedures were performed after written informed consent. The internal database was searched with an in-house-developed software for all consecutive diagnostic angiographies and endovascular treatments of cranial and spinal dAVF in the period between February 2010 to December 2020 (Table 1). All cranial dAVF were classified by Cognard/Merland type 1-5 (Table 2) [4].

\section{Procedure}

All patients of this study cohort underwent diagnostic digital subtraction angiography (DSA) in house or external prior to EVT. DSA was performed to confirm the suspected diagnosis and classify the fistula for further tailoring the appropriate treatment. The decision to perform endovascular intervention was based on a case-by-case evaluation in an interdisciplinary decision-making process between neurosurgeons and interventional neuroradiologists. In the case of primary surgery in patients with spinal dAVF, DSA was

Table 1 Demographic data and classification of dAVF

\begin{tabular}{ll}
\hline Parameter & Number $(\%)$ \\
\hline Number of patients & $131(100 \%)$ \\
Cranial dAVF & $94(72 \%)$ \\
Male/female & $60(64 \%) / 34(36 \%)$ \\
Age (mean, range) & $57,23-83$ \\
Total number of EVT sessions & 111 \\
EVT with Onyx/EASYX & $109(98 \%) / 2(2 \%)$ \\
Frustrated EVT & $5(4 \%)$ \\
Additional platinum coils & $24(22 \%)$ \\
Additional ballon protection & $29(26 \%)$ \\
Additional surgery & $6(6 \%)$ \\
Spinal dAVF & $37(28 \%)$ \\
Male/female & $26(70 \%) / 11(30 \%)$ \\
Age (mean, range) & $70,30-79$ \\
Total number of EVT sessions/number of & $24 / 22(59 \%)$ \\
patients & \\
EVT with Glubran/Onyx & $22(92 \%) / 2(8 \%)$ \\
Frustrated EVT & $3(12 \%)$ \\
Additional platinum coils & $2(8 \%)$ \\
Additional surgery & $4(17 \%)$ \\
Exclusively surgery & $15(41 \%)$ \\
\hline
\end{tabular}

$d A V F$ dural arteriovenous fistula, $E V T$ endovascular therapy 
Table 2 Classification of the 94 patients with cranial dural arteriovenous fistula (dAVF) according to Merland-Cognard Classification

\begin{tabular}{lll}
\hline Fistula type & Drainage pattern & $n(\%)$ \\
\hline 1 & $\begin{array}{l}\text { Drainage into dural venous sinus, antegrade } \\
\text { flow }\end{array}$ & $11(11.7)$ \\
$2 \mathrm{a}$ & $\begin{array}{l}\text { Drainage into dural venous sinus, retrograde } \\
\text { flow }\end{array}$ & $24(25.5)$ \\
$\mathrm{2b}$ & $\begin{array}{c}\text { Drainage into dural venous sinus, antegrade } \\
\text { flow, and cortical venous reflux }\end{array}$ & $1(1.0)$ \\
& $\begin{array}{l}\text { Drainage into dural venous sinus, retrograde } \\
\text { fa }+\mathrm{b}\end{array}$ & $14(14.8)$ \\
3 & $\begin{array}{c}\text { Cortical venous reflux, no venous ectasia } \\
4\end{array}$ & $8(8.5)$ \\
5 & Cortical venous reflux, venous ectasia & $35(37.2)$ \\
\hline
\end{tabular}

performed subsequently for control purposes. All EVTs were performed under general anesthesia.

The standard EVT procedure of cranial dAVFs at our department is described in detail by Moenninghoff et al. [24]. A transfemoral access was gained via a 6-F sheath, and fluoroscopic guided superselective catheterization was performed to reach a wedge position with the microcatheter tip close to the fistula point. Almost all dAVFs were treated as the primary treatment by ethylene vinyl alcohol (EVOH) copolymer (Onyx ${ }^{\circledR}$, Medtronic, Inc., Irvine, USA); only two patients received Easyx (Antia Therapeutics AG, Berne, Switzerland) alternatively. Superselective transarterial embolization technique and a detailed description of the EVOH liquid embolic system are stated in a precursor study of our department [9]. In some cases, an additional coil embolization or balloon protection of the venous sinus via venous transfemoral access was performed.

The standard EVT procedure of spinal dAVFs at our department is described in detail by Özkan et al. [25]. A transfemoral arterial approach was obtained, and under fluoroscopy, a guiding catheter was placed in the segmental artery. A microcatheter was introduced coaxially through the feeding pedicle and advanced into the distal aspect of a feeding artery close to the fistula in the ideal case in wedge-position so that a liquid embolic agent could be pushed up to the proximal venous side. In 20 patients, a mixture of Glubran ${ }^{\circledR}$ (cyanoacrylate glue, GEM s.r.l., Italy) and iodized oil (Lipiodol®, Guerbet, Aulnay-sous-Bois, France) in case-dependently variable concentrations (ranging from 1:3 up to 1:5) for appropriate flow characteristics and in two patients Onyx was injected. Ideally, a continuous injection embolized the feeding pedicle, including the terminal feeders up to the fistulous point, as well as the beginning of the early draining vein. A final spinal angiogram of the initially feeding segmental artery and of the adjacent and contralateral segmental arteries was performed.

The intervention was considered successful if embolization of the dAVF was possible. In a few cases, an endovascular embolization attempt was made, but failed and was considered frustrating.

\section{Biplanar angiography system}

All procedures were performed at the Allura Xper FD20/10 system (Philips Healthcare, Eindhoven, The Netherlands) by an experienced team of neuroradiologists. As we are a university hospital, young neuroradiologists were regularly involved in the interventions in addition to a neuroradiologist with many years of angiography experience. The X-ray unit is equipped with automatic control dose rate system. The frame rate frequently used at pulsed fluoroscopy mode was 1 pulse/s. The focus-to-skin distance varied from 60 to $70 \mathrm{~cm}$. The Allura Xper system has one detector 20-inch with a maximum field of view (FOV) of $48 \mathrm{~cm}$ and one 10 -inch detector with a max. FOV of $25 \mathrm{~cm}$. The deposited protocol for the treatment of dAVF was set at a characteristic tube voltage of $80 \mathrm{kV}$. An anti-scatter grid and an aluminum filter with 1-mm thickness were used. To test system performance and stability over time, periodic quality controls were performed during maintenance visits.

\section{Dose calculation}

Radiation exposure for diagnostic DSA and EVT was determined in terms of dose area product (DAP). To achieve dose optimization in the clinical routine, DRLs are a globally accepted parameter for dose monitoring, in the interventional setting typically defined in terms of the DAP. DRLs represent the 75th percentile of a dose distribution of a specific radiological procedure and may indicate whether the radiation dose lies within the normal range of a dose distribution at radiological departments [26, 27]. The achievable dose (AD) is another important parameter for dose optimization representing the median of a dose distribution [28].

\section{Statistical analysis}

The interventions were analyzed according to the type of procedure and the type of fistula. The mean, median, and 75th percentile of the DAP, as well as the mean fluoroscopy time, were calculated. A $p$-value lower than 0.05 was considered as statistically significant. Statistical analysis was performed with the Statistical Package for Social Sciences v. 27.0. (SPSS Inc., New York, USA). 


\section{Results}

\section{Patient cohort}

Between February 2010 and December 2020, 264 consecutive neurointerventional procedures in 131 patients with dAVF (94 cranial, 37 spinal) were performed in our department. The median age of patients with cranial and spinal dAVF was 60 years (range 23-87 years) and 70 years (range 30-79 years), respectively. The gender distribution in both cohorts was in favor of the male gender (cranial dAVF 60/94; spinal dAVF 26/37). Out of 94 patients with cranial dAVF, 111 EVTs were performed using Onyx/EASYX (109/2). A successful embolization was achieved in 106 out of 111 interventions (95.5\%). Out of 37 patients with spinal dAVF, 22 received EVT with Glubran/ Onyx and 15 patients underwent primary surgery. Embolization was in 21/24 (87.5\%) procedures successful (Table 1).

\section{Radiation exposure and DRLs}

The following DRLs, AD, and mean values could be determined for all patients with dAVF undergoing EVT (I) or diagnostic cerebral angiography (II): for cranial dAVF (I) DRL 507.33 $\mathrm{Gy} \mathrm{cm}^{2}$, AD $369.79 \mathrm{~Gy} \mathrm{~cm}^{2}$, mean $396.51 \mathrm{~Gy}$ $\mathrm{cm}^{2}$; (II) DRL 256.65 $\mathrm{Gy} \mathrm{cm}^{2}$, AD $214.19 \mathrm{~Gy} \mathrm{~cm}^{2}$, mean $211.80 \mathrm{~Gy} \mathrm{~cm}^{2}$; for spinal dAVF (I) DRL $482.72 \mathrm{~Gy}$ $\mathrm{cm}^{2}$, AD $275.98 \mathrm{~Gy} \mathrm{~cm}^{2}$, mean $347.12 \mathrm{~Gy} \mathrm{~cm} \mathrm{~cm}^{2}$; (II) DRL $396.39 \mathrm{~Gy} \mathrm{~cm}^{2}$, AD $210.57 \mathrm{~Gy} \mathrm{~cm}^{2}$, mean $299.55 \mathrm{~Gy} \mathrm{~cm}^{2}$ (Table 3).

\section{Comparison of radiation exposure regarding the type of fistula and procedure}

The Kruskal-Wallis test with Dunn-Bonferroni post hoc test revealed for both cranial and spinal dAVF a significant dose difference regarding the type of procedure $(p<0.001)$ (Fig. 1). No statistical dose difference was found between the different region of fistula (cranial vs. spinal) according to DSA $(p=0.380)$ and EVT $(p=0.472)$. As normal distribution was fulfilled and the Levene's test confirmed the equality of variance between the subgroups Cognard 4 and $2 \mathrm{a}$ in patients with cranial dAVF $(p=0.685)$, the $t$-test was applied. No significant differences of DAP between the two subgroups $(p=0.548)$ were observed. The one-way ANOVA confirmed a significant dose difference between initial DSA and postsurgery DSA in patients with spinal dAVF $(p<0.001)$ (Fig. 2). Excluding the frustrated therapy sessions, no significant difference of DAP was observed for cranial dAVF $(p=0.932)$ or spinal dAVF $(p=0.076)$. Likewise, no significant difference of DAP was found for cranial dAVF ( $p=0.151)$ or spinal dAVF $(p=0.873)$ by excluding all the patients who underwent more than one therapy session.

The mean fluoroscopy times (FT) are listed in Table 3. Spearman correlations were run to assess the linear relationship between DAP and FT for DSA and EVT (Fig. 3).

\section{Discussion}

Our study analyzes radiation exposure of fluoroscopy-guided angiographies of patients with dAVF and reveals useful dose data differentiated by the type of fistula, anatomical region of fistula, and procedure. The results may be used as a benchmark for the national radiation protection authorities to implement DRLs in the EVT of cranial and spinal dAVF as proposed by the European Directive 2013/59/Euratom [23].

With regard to interventional neuroradiology, until now, the German Federal Office for Radiation Protection only published DRLs for thrombus aspiration (DRL 180.0 Gy $\mathrm{cm}^{2}$ ) and aneurysm coiling (DRL 250.0 Gy cm${ }^{2}$ ) [29]. For dAVF embolization, only few authors addressed the issue of radiation exposure at all. Forbig et al. provided detailed dosimetry data for the endovascular treatment of intracranial lateral dAVF differentiated by the Cognard grade and endovascular technique [30]. The proposed DRLs are slightly lower compared to our study (DRL $414.0 \mathrm{~Gy} \mathrm{~cm}^{2}$ ). This is probably related to the strict selection criteria. In our study, we also excluded other intracranial fistulae, such as CCF. However, in their study, anterior crainal fossa dAVF were also excluded. Other studies neither yielded information
Table 3 Distribution of total DAP as a function of procedure type and dural arteriovenous fistula site

\begin{tabular}{|c|c|c|c|c|c|c|c|}
\hline \multirow[t]{2}{*}{ Location of dAVF } & \multirow{2}{*}{$\begin{array}{l}\text { Type of } \\
\text { proce- } \\
\text { dure }\end{array}$} & \multirow[b]{2}{*}{$\mathbf{n}$} & \multicolumn{4}{|c|}{ Total DAP $\left(\mathrm{Gy} \mathrm{cm}^{2}\right)$} & \multirow{2}{*}{$\begin{array}{l}\text { FT } \\
\text { Mean }\end{array}$} \\
\hline & & & 25th percentile & Median & 75th percentile & Mean & \\
\hline \multirow[t]{2}{*}{ Cranial } & DCA & 71 & 129.57 & 214.19 & 256.65 & 211.80 & $17 \min 18 \mathrm{~s}$ \\
\hline & EVT & 111 & 264.65 & 369.79 & 507.33 & 396.51 & $58 \min 57 \mathrm{~s}$ \\
\hline \multirow[t]{2}{*}{ Spinal } & DCA & 58 & 125.57 & 210.57 & 396.39 & 299.55 & $25 \min 33 \mathrm{~s}$ \\
\hline & EVT & 24 & 169.37 & 275.98 & 482.72 & 347.12 & $35 \min 45 \mathrm{~s}$ \\
\hline
\end{tabular}

$D C A$ diagnostic cerebral angiography, $D A P$ dose area product in gray per square centimeter, $d A V F$ dural arteriovenous fistula, $E V T$ endovascular treatment, $F T$ fluoroscopic time in minutes, $n$ number of studies 

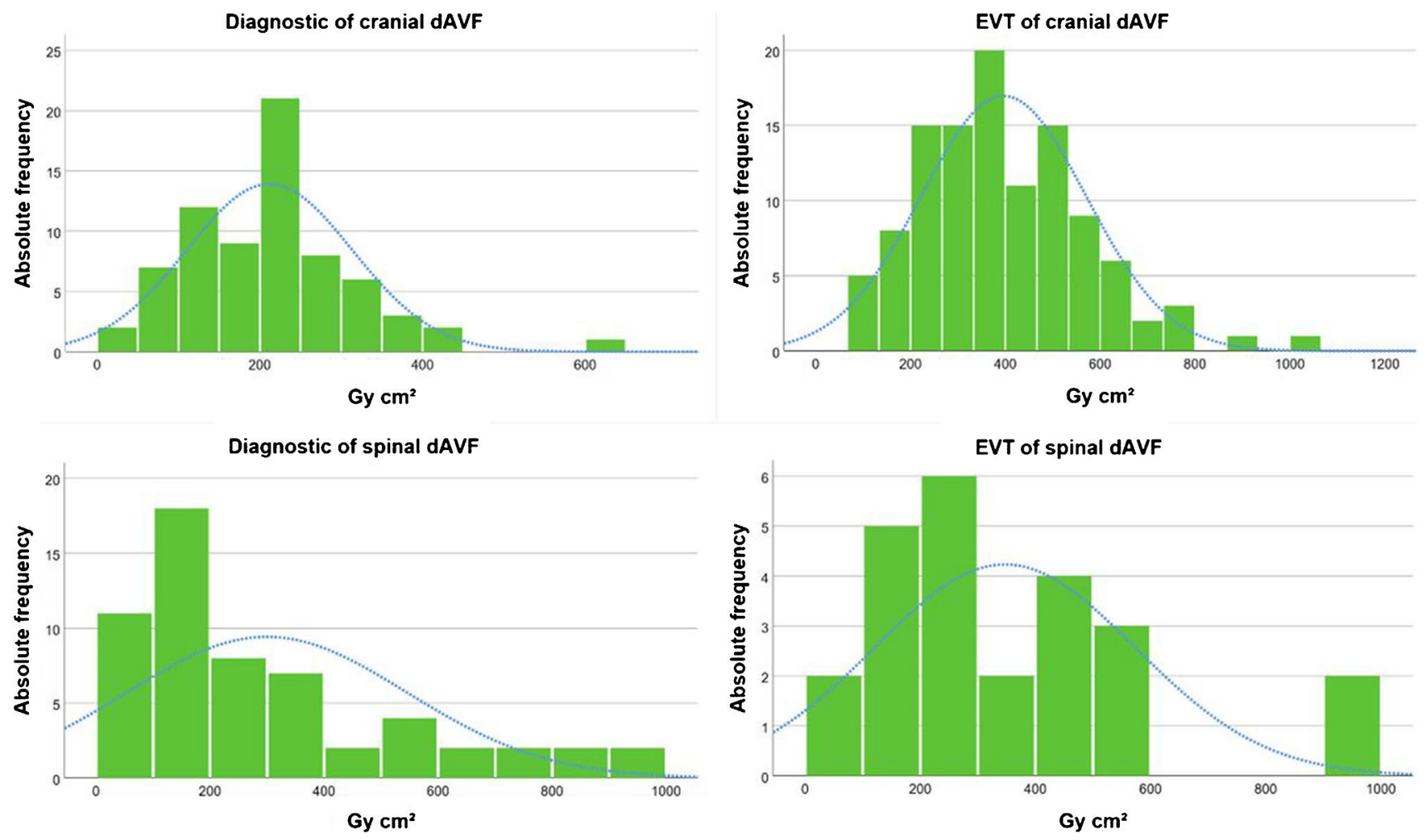

Fig. 1 Histogram of dose area product $\left(\mathrm{Gy} \mathrm{cm}^{2}\right)$ for diagnostic DSA and endovascular therapy (EVT) of cranial and spinal dAVF; blue curve highlighting distribution graph

concerning the dedicated type of dAVF nor the applied endovascular approach [31,32].

The local DRLs determined in our study (dAVF cranial $507.3 \mathrm{~Gy} \mathrm{~cm}^{2}$ and spinal $482.7 \mathrm{~Gy} \mathrm{~cm}^{2}$ ) are higher, but in the range of the published data of other studies describing the radiation exposure of AVM embolization only, e.g., Miller et al. (479,2 Gy $\mathrm{cm}^{2}$ cranial AVM, 476,3 Gy $\mathrm{cm}^{2}$ spinal AVM) and Kien et al. (440 Gy $\mathrm{cm}^{2}$ cranial AVM) $[33,34]$. Since EVT of both cerebrovascular malformations are complex neurointerventional procedures with a similar therapeutic approach, it may not surprise that our DRLs are in a similar range.

As shown in previous studies, the amount of radiation for interventional procedures is much more affected by procedure complexity than by patient size and weight [35]. Therefore, DRLs for interventional procedures should be ideally established according to the type and complexity level of the procedure. Although the EVT of cranial and spinal dAVF is performed in different anatomical regions, the therapeutic approach is similar, and both are complex interventional procedures. This may explain why we could not find any significant dose differences in the EVT of both fistula types in our cohort. Since our DRLs are in a similar range to the published local DRLs for embolization of AVM, it is worth discussing whether DRLs should be defined under the umbrella term EVT of cerebrovascular malformations.

The failure of a dAVF embolization only becomes apparent in the course of the procedure and frustrated fluoroscopyguided therapy sessions can involve a similarly high radiation dose as successful procedures. This may explain why in our study no significant difference of DAP was found by excluding the frustrated therapy sessions.

Excluding all the patients who underwent more than one therapy session did not affect the total DAP in the EVT of cranial and spinal dAVF. However, most patients received only one therapy session, so conclusions about dose differences are obsolete.

As shown in Figs. 2 and 3, there is a linear correlation between the DAP and the FT, but the FT is a poor predictor of dose to the patient, because it does not account for the effects of image acquisition modes. To estimate stochastic risks of radiation exposure, the effective dose is a more straightforward value [36]. However, to compare radiation 

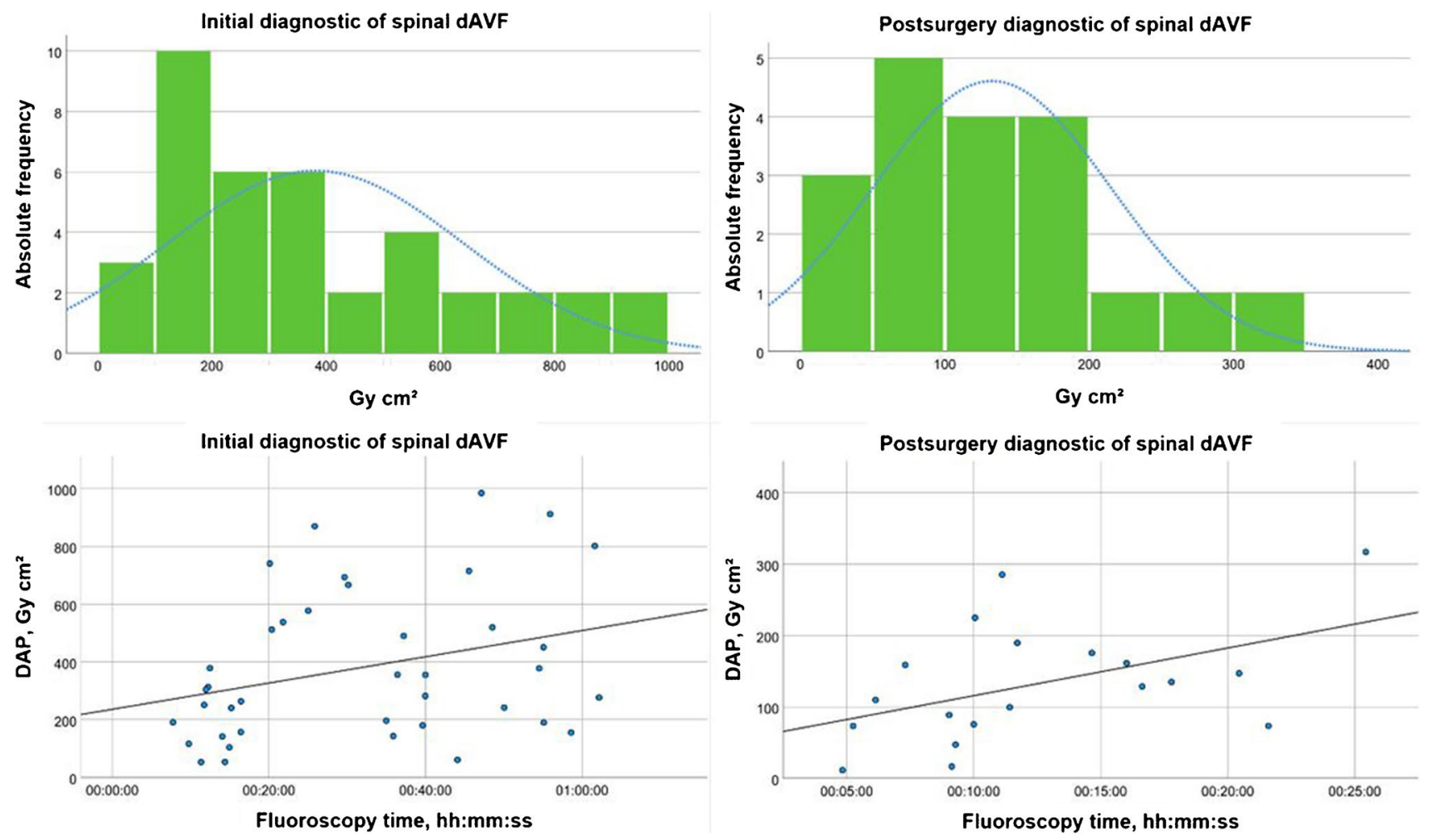

Fig. 2 Histogram of dose area product $\left(\mathrm{Gy} \mathrm{cm}^{2}\right)$ and scatter plot with adjustment line between dose area product (DAP) and fluoroscopy time for initial and postsurgery diagnostic DSA in patients with spinal dAVF

exposure of different devices at different sites in the clinical routine, DRLs are a practical and a globally accepted parameter for dose monitoring.

Patients with spinal dAVF received an initial DSA and in some cases also a postoperative control DSA to ascertain successful elimination of the fistula. The initial DSAs are more time-consuming in clinical routine and usually require more sequences due to the complexity of the disease. For this reason, it is not surprising that a significantly higher dose was determined for the initial DSA compared to the post-surgery DSA (Fig. 2).

Cranial dAVF type $2 \mathrm{a}$ are confined to sinus, and consequently, the fistula point is easier to reach than in type 4 fistula, which drains directly into cortical veins. However, with regard to radiation exposure, no significant difference was found in our study. Consequently, it does not seem to be useful to distinguish DRLs between the different fistula types according to Cognard.

It is striking that the gender distribution in our study clearly favors the male gender. This finding is consistent with studies that have shown that men are more prone to cranial and spinal dAVF than women [24, 37].

The most important limitation of our study is the retrospective and unicenter design with different cohort sizes. Our determined dose levels may differ from those of other sites and angiography devices. Therefore, the examination of radiation exposure at different sites and devices are the next necessary steps for the determination of national and European DRLs. An experienced team of neuroradiologists performed all procedures, but on a university hospital, young neuroradiologists are also trained. In terms of radiation dose, our results therefore may indicate higher doses than can possibly be achieved.

Strengths of our study include the large number of datasets collected on the same biplanar angiography system enabling specific dose assessment. To determine local DRLs for a single center, it is recommend by Vano et al. to collect the radiation data of more than 50 examinations within the same type of procedure because of the high individual variability of interventional procedures [38]. In this study, the number of procedures was greater than 50 for the EVT of cranial dAVFs. In rare interventional procedures, DRLs may also be determined for more than 20 examinations, as in our study for the EVT of spinal dAVF. 

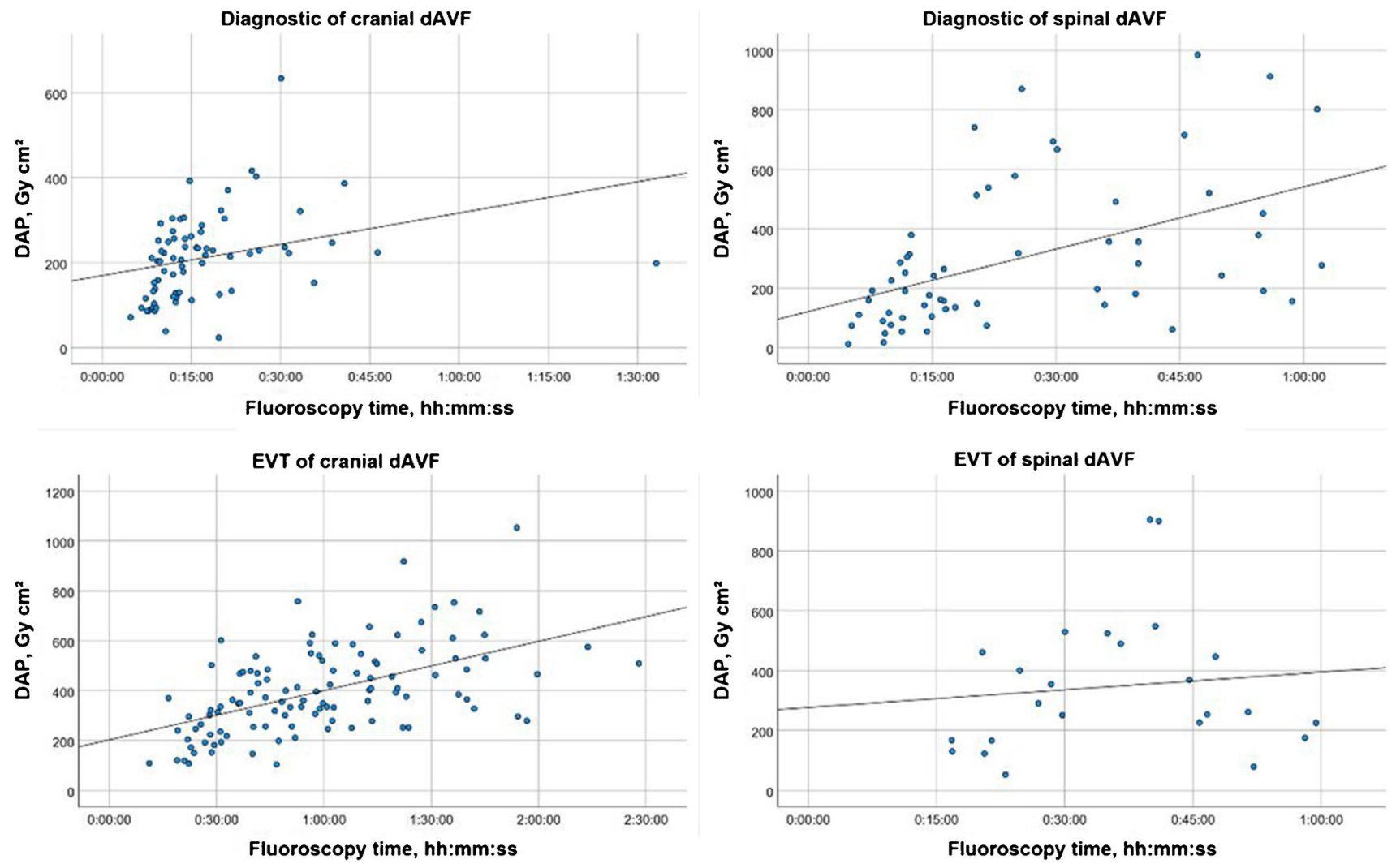

Fig. 3 Scatter plot with adjustment line between dose area product (DAP) and fluoroscopy time for diagnostic DSA and endovascular therapy (EVT) of cranial and spinal dAVF

\section{Conclusion}

Increasing regulatory requirements necessitate dose monitoring of patients and staff members, and justification of aberrant exposures. This is the first comprehensive data acquisition of radiation exposure during dAVF therapy in a neuroradiology referral centre, which explicitly distinguishes between EVT of cranial and spinal dAVF. Although EVT was performed in two different anatomical regions, no significant dose difference was found between the two entities. Because radiation exposure to comparably complex interventions such as AVM embolization is similar, it may be useful to determine general DRLs for both entities together.

Funding Open Access funding enabled and organized by Projekt DEAL. No funding was received for this study. D. Bos was supported as a Clinician Scientist within the University Medicine Essen Academy (UMEA) program, funded by the German Research Foundation (DFG; grant FU356/12-1) and the Faculty of Medicine, University of Duisburg-Essen.

\section{Declarations}

Ethical approval All procedures performed in the studies involving human participants were in accordance with the ethical standards of the institutional and/or national research committee and with the 1964 Helsinki Declaration and its later amendments or comparable ethical standards.

Informed consent For this type of retrospective study, formal consent is not required and all patient data was anonymized.

Conflict of interest The authors declare no competing interests.

Open Access This article is licensed under a Creative Commons Attribution 4.0 International License, which permits use, sharing, adaptation, distribution and reproduction in any medium or format, as long as you give appropriate credit to the original author(s) and the source, provide a link to the Creative Commons licence, and indicate if changes were made. The images or other third party material in this article are included in the article's Creative Commons licence, unless indicated otherwise in a credit line to the material. If material is not included in the article's Creative Commons licence and your intended use is not permitted by statutory regulation or exceeds the permitted use, you will need to obtain permission directly from the copyright holder. To view a copy of this licence, visit http://creativecommons.org/licenses/by/4.0/.

\section{References}

1. Wanke I, Rüfenacht DA (2015) The dural AV-fistula (DAVF), the most frequent acquired vascular malformation of the central 
nervous system (CNS). Clin Neuroradiol. https://doi.org/10.1007/ s00062-015-0449-0

2. Gandhi D, Chen J, Pearl M et al (2012) Intracranial dural arteriovenous fistulas: classification, imaging findings, and treatment. Am J Neuroradiol. https://doi.org/10.3174/ajnr.A2798

3. Duffau H, Lopes M, Janosevic V et al (1999) Early rebleeding from intracranial dural arteriovenous fistulas: report of 20 cases and review of the literature. J Neurosurg. https://doi.org/10.3171/ jns.1999.90.1.0078

4. Cognard C, Gobin YP, Pierot L et al (1995) Cerebral dural arteriovenous fistulas: clinical and angiographic correlation with a revised classification of venous drainage. Radiology. https://doi. org/10.1148/radiology.194.3.7862961

5. In 'T Veld M, Fronczek R, De Laat JA et al (2018) The incidence of cranial arteriovenous shunts in patients with pulsatile tinnitus: a prospective observational study. Otology and Neurotology. https:// doi.org/10.1097/MAO.0000000000001767

6. Deuschl C, Göricke S, Gramsch C et al (2015) Value of DSA in the diagnostic workup of pulsatile tinnitus. PLoS ONE. https:// doi.org/10.1371/journal.pone.0117814

7. Cognard C, Januel AC, Silva NA, Tall P (2008) Endovascular treatment of intracranial dural arteriovenous fistulas with cortical venous drainage: New management using onyx. Am J Neuroradiol. https://doi.org/10.3174/ajnr.A0817

8. Trivelato FP, Abud DG, Ulhôa AC et al (2010) Dural arteriovenous fistulas with direct cortical venous drainage treated with Onyx ${ }^{\circledR}$ : a case series. Arq Neuropsiquiatr. https://doi.org/10.1590/ s0004-282x2010000400025

9. Panagiotopoulos V, Möller-Hartmann W, Asgari S et al (2009) Onyx embolization as a first line treatment for intracranial dural arteriovenous fistulas with cortical venous reflux. RoFo Fortschritte auf dem Gebiet der Rontgenstrahlen und der Bildgebenden Verfahren. https://doi.org/10.1055/s-2008-1027901

10. Thron A (2001) Spinale durale arteriovenöse fisteln. Radiologe. https://doi.org/10.1007/s001170170031

11. Kai Y, Hamada J, Morioka M, Yano S, Mizuno T, Kuratsu J (2005) Arteriovenous fistulas at the cervicomedullary junction presenting with subarachnoid hemorrhage: six case reports with special reference to the angiographic pattern of venous drainage. AJNR Am J Neuroradiol 26:1949-1954

12. Aminoff MJ, Barnard RO, Logue V (1974) The pathophysiology of spinal vascular malformations. J Neurol Sci. https://doi.org/10. 1016/0022-510X(74)90229-9

13. Aminoff MJ, Logue V (1974) The prognosis of patients with spinal vascular malformations. Brain. https://doi.org/10.1093/brain/ 97.1.211

14. Gemmete JJ, Chaudhary N, Elias AE et al (2013) Spinal dural arteriovenous fistulas: clinical experience with endovascular treatment as a primary therapy at 2 academic referral centers. Am J Neuroradiol. https://doi.org/10.3174/ajnr.A3522

15. Inagawa $S$, Yamashita $S$, Hiramatsu $H$ et al (2013) Clinical results after the multidisciplinary treatment of spinal arteriovenous fistulas. Jpn J Radiol. https://doi.org/10.1007/s11604-013-0216-6

16. Schegerer A, Loose R, Heuser LJ, Brix G (2019) Diagnostic reference levels for diagnostic and interventional X-ray procedures in Germany: update and handling. RoFo Fortschritte auf dem Gebiet der Rontgenstrahlen und der Bildgebenden Verfahren. https://doi. org/10.1055/a-0824-7603

17. Schegerer A (2018) Bundesamt für Strahlenschutz: Bekanntmachung der aktualisierten diagnostischen Referenzwerte für interventionelle Röntgenanwendungen. In: 16.08.2018. https://www. bfs.de/SharedDocs/Downloads/BfS/DE/fachinfo/ion/drw-aktua lisierung.pdf?__blob=publicationFile $\& v=3$. Accessed 18 Mar 2021

18. Vano E, Fernandez JM, Sanchez RM et al (2013) Patient radiation dose management in the follow-up of potential skin injuries in neuroradiology. Am J Neuroradiol. https://doi.org/10.3174/ajnr. A3211

19. Tavares JB, Sacadura-Leite E, Matoso T et al (2016) The importance of protection glasses during neuroangiographies: a study on radiation exposure at the lens of the primary operator. Interv Neuroradiol. https://doi.org/10.1177/1591019916628322

20. Rajaraman P, Doody MM, Yu CL, et al (2016) Cancer risks in U.S. radiologic technologists working with fluoroscopically guided interventional procedures, 1994-2008. American Journal of Roentgenology. https://doi.org/10.2214/AJR.15.15265

21. Mountford PJ, Temperton DH (1992) Recommendations of the International Commission on Radiological Protection (ICRP) 1990. Eur J Nucl Med. https://doi.org/10.1007/BF00184120

22. Teunen D (1998) The European Directive on health protection of individuals against the dangers of ionising radiation in relation to medical exposures (97/43/EURATOM). J Radiol Prot. https://doi. org/10.1088/0952-4746/18/2/009

23. Council of the European Union (2013) Council Directive 2013/59/ Euratom. Off J Eur Union. https://doi.org/10.3000/19770677.L_ 2013.124.eng

24. Moenninghoff C, Pohl E, Deuschl C et al (2020) Outcomes after onyx embolization as primary treatment for cranial dural arteriovenous fistula in the past decade. Acad Radiol. https://doi.org/10. 1016/j.acra.2019.07.021

25. Özkan N, Kreitschmann-Andermahr I, Goerike SL et al (2015) Single center experience with treatment of spinal dural arteriovenous fistulas. Neurosurg Rev. https://doi.org/10.1007/ s10143-015-0645-z

26. International Atomic Energy Agency (2014) Radiation protection and safety of radiation sources: International Basic Safety Standards (GSR Part 3). International Atomic Energy Agency Vienna. STI/PUB/1578

27. Guberina N, Forsting M, Suntharalingam S et al (2016) Radiation dose monitoring in the clinical routine. RöFo - Fortschritte auf dem Gebiet der Röntgenstrahlen und der bildgebenden Verfahren. https://doi.org/10.1055/s-0042-116684

28. National Council on Radiation Protection and Measurements (NCRP) (2012) Reference levels and achievable doses in medical and dental imaging: recommendations for the United States. Psychological Bulletin.1037//0033-2909.I26.1.78

29. Schegerer A, Loose R, Heuser L, Brix G (2019) Diagnostische Referenzwerte für diagnostische und interventionelle Röntgenanwendungen in Deutschland: Aktualisierung und Handhabung. Fortschr Röntgenstr. https://doi.org/10.1055/a-0824-7603

30. Forbrig R, Stahl R, Geyer LL et al (2020) Radiation dose and fluoroscopy time of endovascular treatment in patients with intracranial lateral dural arteriovenous fistulae. Clin Neuroradiol. https://doi.org/10.1007/s00062-020-00982-3

31. Hassan AE, Amelot S (2017) Radiation exposure during neurointerventional procedures in modern biplane angiographic systems: a single-site experience. Interventional Neurology. https://doi.org/ $10.1159 / 000456622$

32. Van Der Marel K, Vedantham S, Van Der Bom IMJ et al (2017) Reduced patient radiation exposure during neurodiagnostic and interventional X-ray angiography with a new imaging platform. Am J Neuroradiol. https://doi.org/10.3174/ajnr.A5049

33. Miller DL, Kwon D, Bonavia GH (2009) Reference levels for patient radiation doses in interventional radiology: proposed initial values for U.S. practice. Radiology. https://doi.org/10.1148/ radiol.2533090354

34. Kien N, Rehel JL, Étard C, Aubert B (2011) Patient dose during interventional neuroradiology procedures: results from a multicenter study. J Radiol. https://doi.org/10.1016/j.jradio.2011.08. 005

35. Balter S, Miller DL, Vano E et al (2008) A pilot study exploring the possibility of establishing guidance levels in $\mathrm{x}$-ray 
directed interventional procedures. Medical Physics DOI 10(1118/1):2829868

36. Harrison JD, Streffer C (2007) The ICRP protection quantities, equivalent and effective dose: Their basis and application. Radiat Prot Dosimetry. https://doi.org/10.1093/rpd/ncm248

37. Forsting, Michael, Jansen O (2014) Spinale Gefäßmalformationen mit arteriovenösem Shunt. In: MRT des Zentralnervensystems

38. Vano E, Järvinen H, Kosunen A et al (2008) Patient dose in interventional radiology: a European survey. Radiat Prot Dosimetry. https://doi.org/10.1093/rpd/ncn024
Publisher's note Springer Nature remains neutral with regard to jurisdictional claims in published maps and institutional affiliations. 